\title{
ISTATISTIKSEL DÜŞÜNME Veri Analizinden Hemen Önce
}

Ümit Remzi ERGÜN

Elif BULUT 


\title{
(C) Copyright 2021
}

Bu kitabın, basım, yayın ve satış hakları Akademisyen Kitabevi A.Ş.'ne aittir. Anılan kuruluşun izni alınmadan kitabın tümü ya da bölümleri mekanik, elektronik, fotokopi, manyetik kağıt ve/veya başka yöntemlerle çoğaltılamaz, basılamaz, dağıtılamaz. Tablo, şekil ve grafikler izin alınmadan, ticari amaçh kullanılamaz. Bu kitap T.C. Kültür Bakanlı̆ı bandrolü ile satılmaktadır.

\section{ISBN}

978-625-7496-68-1

\author{
Kitap Adı \\ İstatistiksel Düşünme \\ Veri Analizinden Hemen Önce \\ Yazar \\ Ümit Remzi ERGÜN \\ ORCID iD: 0000-0002-8967-1892 \\ Elif BULUT \\ ORCID iD: 0000-0001-8278-1821
}

Yayın Koordinatörü

Yasin DILLMEN

Sayfa ve Kapak Tasarımı

Akademisyen Dizgi Ünitesi

\section{Yayıncı Sertifika No}

47518

Baskı ve Cilt

Vadi Matbaacılık

Bisac Code

SOC027000

DOI

XXX

\section{GENEL DAĞITIM} Akademisyen Kitabevi A.Ş.

Halk Sokak 5 / A

Yenişehir / Ankara

Tel: o312 4311633

siparis@akademisyen.com 


\section{YAZAR SUNUŞU}

\section{Ümit Remzi ERGÜN}

Ustalığa ilişkin sevdiğim tanımlardan biri "ustalık, karşısındaki kişide 'ne kadar kolaymış ben de yapabilirim' hissi uyandırmaktır," der. Bu kitabın bana ait bölümlerinin hazırlığındaki tüm çalışmalarımın başlangıç noktası da aynı histir. Dünyanın en değerli yerlerinden birinin mezarlıklar olduğunu, hayata geçmemiş birçok projenin orada yattığı inancıyla kabul etmekteyim. Bu eserde kaleme aldığım bölümler Çanakkale Onsekiz Mart Üniversitesi'nde başladığım yüksek lisans eğitimimde neler öğrendiğimin, neleri anladığımın ve neyin farkına vardığımın iç dökümüdür. Hayatımdaki projelerden birinin de mezarlıklarda yatmaması adına yazılmıştır.

Hazırlığını yaptığım bölümlerde okunacak olan metinler bu alanda çalışan bilim insanlarının, bir başka deyişle ustaların alanına izinsiz girmiş bir kişinin veri bilimine dair gözlemlerinden oluşmaktadır. Anadolu coğrafyasında kaleme aldığım bölümlerde, bu izinsiz girişi Anadolu kültürüne ait "göz hakkı" kavramıyla eşleştirerek bu alanda daha teknik ve bilimsel çalışmalar yapan bilim insanlarının affına sı̆̆ınıyorum.

Yazdığım ve derlediğim her bilgi "öğretici ve açıklayıcı" özellikli olmaktan çok uzak, veri bilimi konusunda benim neyi, nasıl anladığ1ma, ne ile anlamlandırdığıma ve ne olursa daha iyisi olur sorusuna yanıt aradığıma dair cümlelerden oluşmaktadır. Kantitatif içerikli bir konuda formüller ve göstergeler yerine cümlelerin tercih edilmesi, cümle kavramının eş anlamlısının küme kabul edilmesiyle ve cümlenin matematiğin temel fikri olduğunun savunulmasıyla bağlantılıdır. Belirli bir evrendeki doğru tanımlanmış ve doğru anlamlandırılmış nesneler koleksiyonu, kaleme aldığım bölümlerdeki cümlelerin genel tanımıdır.

Sosyal bilimler ve istatistiksel bilgilerin birbirinden uzaktan çok uzak görülmesine rağmen yaklaştıkça birbirine çok yakın konumlanması, sos- 
yal bilimlerde çalışma yapan veya sosyal bilim öğrenenlerin cebirsel kaygılarını kovuşturmak için yeterlidir. Sosyal bilimler en genel anlamıyla sadece öğrenenine başlıklar halinde sunduğu konuları bilgiyle aktarmayı yeğlemez, tam aksine öğrenenin sosyal düşüncesini geliştirmeyi ve uygulayabilme istencini arttırmayı da güdüler. Sadece kantitatif biçimde hızlı sayısal tespit yetisi ya da sosyal sorunlarda hızlı çözüm yolu tespiti tek başına ne kadar yeterlidir, bir başka soruyla; ne kadar doğru sonuç elde ettirir? Yazıya döktüğüm bölümler sosyal bilimler ve istatistik arasında bilgilerin harmanlandığı dibek taşı; bu alanda yapılan çalışmaların kalitesini ölçen bir mihenk taşı ya da uzun soluklu çalışmaların sonucunu gösterir bir kilometre taşı değildir. Tüm metinler sosyal bilimler ve istatistiksel bilgilerin taraflarını dengede tutan bir kilit taşı görevini üstlenmiştir.

Uzun bir dönem boyunca grafikler, göstergeler ve yan yana halay çeker düzende dizili rakamlardan geri duran biri olarak sorumlusu olduğum bölümlerin yazıya dökülmesi herkesten önce benim kendime karşı duyduğum büyük bir şaşkınlığın sonucunda ortaya çıkmıştır. Oluşturulan her içerikte herhangi bir konuda sayısal verilerin, 90'lı yılların bol çiçekli halı deseni gibi gözümün önünde durmasının zihnimi bulanıklaştırmasına, Yönetim Ekonomisi gibi bu verilerin doğru yorum ve doğru yöntemle uygulanması gerektiği bir alanda öğrenen olarak kalem tükenmediğince izin vermek istemedim.

Tarih, ilk ve son zamanı belli, kendi periyodunda ayrı bir özellik taşıyan uzun yıllar süresini çağ olarak adlandırmıştır. İçinde bulunduğumuz dönemin teknoloji, uzay, bilim, ve milenyum çağı olarak belirlenmesi öngörüsünün aksine "araştırma çağı" isminin çok daha yerinde olacağı kanaatindeyim. Ülkemizde özellikle 1960 sonrası gündeme alınan planlı kalkınma dönemlerinden bugüne gerçeklerin bilimsel araşıtrmalarla ortaya çıkarılarak çözümlenmesinde ve çözüm yollarının bulunmasında veri bilimindeki ve setlerindeki hızlı değişim, araştırmanın ve araştırmacının "en önemli" sıfatına haiz olduğunun göstergesi değil midir? Bu sorunun cevabındaki kararsızlğı̆n giderilmesi için Tarihçe ve Temel Kavramlar başlı̆̆ının yazılmasını üstlendim. 
Öğrenme süreci devam eden bir öğrenen olarak, okuyucunun örneğin ekonomiye dair söz söyleyenlerin bulunduğu bir mecliste "döviz kuru, endeks ve parite" konularında, direnç noktaları ile teknik konuşmalar yapılırken, benim gibi örneğin "petrol fiyatı yükselirse hisse senetleri düşer," cümlesini kurup kenara çekilmesine kalem yazdığınca engel olmak istedim. 5 Nisan, 24 Ocak gibi kararlarda, ana haber bültenlerinde geçen faiz politikası ifadeleri ve diğer iktisadi sayılarda, göç, sağlık, eğitim gibi veri içerikli konu açıklamalarında okuyucuyu politikacı politikası, spiker sözü, bilim insanı yorumu ve araştırmacı yazısı dört duvarından çıkarak hanehalkının da değişkenler arası ilişkilerde asgari bilgi sahibi olması gereğini savundum. Bu savin gereği olarak da kitabın İstatistiksel Okuryazarlık bölümünün hazırlığını üstlendim.

Beş kıtadan oluşan "büyük köy"de "nitelikli vatandaş" oluşturmak için çaba sarf eden tüm bilim insanlarının huzurunda saygıyla eğiliyorum. Kaleme aldığım her kelimeyi çocuklarının gözüne mutlu ve canlı bakarken, dış dünyaya gözlerini daldırarak, ay sonunu getirebilme hesabı yapan işçi ailelerine ithaf ediyorum.

Daha iyisi için, okuyucudan ve öğrenendaşımdan gelen her eleştiri büyük önem taşımaktadır. Geri bildirimlerinizi esirgemeyiniz.

Behçet Necatigil'in "Kitaplarda Ölmek" şiirinden alıntılar ile sunuş bölümünü tamamlıyorum;

"Adı, soyadı

Açllı parantez

Doğduğu $y^{\prime} l$, çizgi, öldü̆̆ü $y l l$, bitti

Kapanır parantez

(...)

Parantezin içindeki çizgi

Ne varsa orada"

(...)

Ümit Remzi ERGÜN Mart 2021 Samsun 


\section{YAZAR SUNUŞU}

\section{Elif BULUT}

Kişinin eğitim hayatında yer alan kırılma noktalarının varlığı, eğitim sonrası süreçlerinin belirlenmesinde önemli rol oynamaktadır. Temel eğitim süreçlerinde aile, yaşanılan çevre, okul puanı ve ders seçimi gibi etkenlerin belirleyiciliğini, üniversite sürecinde ise sınav puanı, kurum yap1s1, öğretim üyesi, okunmak istenen bölüm gibi etkenler devralmaktadır. Sayısal ya da sözel bölümde öğrenci olmak bu anlamda öğrencinin isteğine, becerisine ve becerilerinin yatkınlı̆̆ına göre belirlenmektedir.

İktisadi ve idari bilimler, toplum bilimleri, sosyal ve beşeri bilimler gibi fakültelerin öğrenci adayları kayıt süreçlerinde hangi derslerin olduğunu, hangi öğretim üyesinden hangi dersi alacağını ve hangi bilim dallarından faydalanacağını incelemektedir. İşletme bölümü üzerinden örneklendirilecek olunursa, kooperatifçilik, ticaret hukuku, üretim yönetimi, pazarlama, yönetim organizasyon ve muhasebe başta olmak üzere bir çok bilim dalı ile karşılaşmanın heyecanı yaşanabilir. Ana bilim dalı listesinde yer alan "sayısal yöntemler" başlığı bir sosyal bilimci için hayal kırıklığı veya şaşkınlık olarak değerlendirilmeli midir?

Kitabın sorumlu olduğum bölümlerini yazarken edindiğim amaç bunun bir hayal kırıklığı veya şaşkınlık olma durumunu bertaraf etmek oldu. Deneyimlediğim birçok olaydan ve aldığım geri bildirimlerden elde ettiğim odak ise öğrencilerimin "benim matematik temelim pek iyi değildir, şimdi istatistiği nasıl yapayım," düşüncesinde bulunmalarıydı. Bu anlamıyla yazdığım bölümlerde ne anlattığımdan çok, neyi neden anlattığıma ağırlık vermeye çalıştım.

Eğitim ve eğitim sonrası hayatımızın kırılma noktalarında bu kaygılar konusunda gerçekten haklı mıyız? Yüksek öğrenim sınavı ile bö- 
lüme kayıt yaptıran öğrenci adaylarının, 2020 y1lında temel yeterlilik testinde matematik için kırk sorudan beş buçuk soru ortalamasında oldukları tespit edilmiştir. Bu cümlede ortalama ifadesi ve sayısal bilgi görüldüğü üzere kullanılmıştır. Kullandığımız cep telefonlarının internet paketlerinin düşüş hızlarını teknik bir dille veri tüketimi olarak isimlendiriyoruz. Dönem, ara, dönem sonu gibi snavlar hakkında konuşurken "hocam çan olacak mı" sorusuyla, biraz evvel verilen iki açıklamayı da gölgede bırakacak kadar güçlü bir örnek vermiş oluyoruz. Öyleyse iktisadi, idari, beşeri ve sosyal bilimlerde istatistik, sayısal yöntemler ve veri bilimine dair kavramlara neden şą̧ırıyoruz?

Ezcümle şaşkınlık veya hayal kırıklığ olarak ifade ettiğim bu durum, sistemin içerisinde varlığını baskın bir şekilde koruyan bir konumdadır. Yayına hazırladığım bölümlerdeki görevim istatistikle ve veri bilimleriyle ilk kez ilgilenmeye ve öğrenmeye başlayanlar için geniş bilgi sunmak, onları belirli bir seviyeye taşımak değildir. Aksine alınan bilginin uygulama örnekleri, daha farklı ifadelerle aktarılmış haliyle sunulması, uygulanabilir ve günlük hayattan örnekler ile pekiştirilmesidir.

Elinizdeki bu kitapta hazırladığım her bölüm için dünyanın en prestijli üniversitelerinin kaynaklarından veri bilimine dair tüm tanım, soru ve açıklama metinlerini derleyebilir; teori, kuram, kural ve birden fazla verinin gösterildiği renkli grafikler sunabilirdim. Bir başka düşüncede ders destek kitabı formatında da hazırlayabilir, hali hazırda sunulan örnekleri tekrarlayabilir veya belirli bir alanda istatistiksel çalışmanın nasıl yapılması gerektiğine dair yöntemlerden bahsedebilirdim. $\mathrm{Bu}$ şekilde hazırlanmış bir kitabın istatistik bilimi için sizce de beşeri ve sosyal yönünü göz ardı etmiş olmayacak mıydım? Bütün bunların uzağında okuyucunun istatistiği kendi ilgi alanında kendisinin kullanabileceği bir yeteneğe dönüştürmeyi hedefledim.

Kitabın hazırlanmasından raflarda yerini almasına kadar geçen sürede ve hatta her bir sayfasının yazılması arasında geçen daha kısa süre- 
de gerçek dünyada ne kadar büyük bir veri tüketildiğini düşündünüz mü? Saatlik değiş̧en piyasalar, kameralar, telefona düşen bildirimler, marketlerin indirime giren ürünleri, uzay çalı̧̧maları... İstatistik ve veri biliminin birbiriyle rekabet mi ettiği yoksa birlikte mi hareket ettiğine dair sonucu okuyucunun takdirine bırakıyorum.

İstatistik ve matematik arasındaki fark nedir? Bu soru öğrenciler tarafından öğretmenlerine o kadar çok sorulmaktadır ki... Henüz dönem başında istatistik dersi kapsam ve içeriğini üst sınıflardan öğrenen her öğrenci "benim matematik temelim yok ki hocam istatistiği yapabileyim" şeklinde geri bildirim vermektedir. Hatta bir dersimde b,r öğrencim "hocam biz üniversite sınavinda eksi matematik ile buraya kayıtlandık, bizden sayısal derslerde nasıl başarı bekliyorsunuz" diye tepki göstermişti. Matematik veya istatistik neden sosyal derslerden bu kadar farklı algilanıyor? Sosyal branşlar gibi bu iki bilim de okuduğunu anlama ve mantık üzerine kurulu değil midir? Öyleyse sunuş bölümünde yer verilmesi gereken dilek "iyi okumalar" olmalıdır.

Yazılan, yapılan, çözülen, araştırılan her çalışmanın anlam kazanması özelleştirilmiş farkındalıklar ile mümkündür. Bir başka deyişle, bir çalı̧smaya anlam yüklemek anlam yaratılabilecek özellikleri elde etmek ile mümkündür. Hazırlanan bu eser çalı̧masının konusu ne olursa olsun istatistikle ve veri bilimiyle çalşanın emeğine bu özellikleri yüklemeyi hayal etmiştir.

Elif BULUT

Mart 2021 Samsun 


\section{iÇiNDEKILER}

1.Bölüm Tarihçe ve Temel Kavramlar

Ümit Remzi ERGÜN

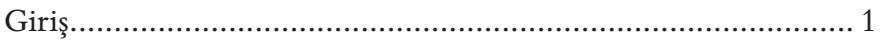

İstatistiğin Tarihçesi.............................................................. 1

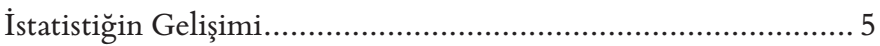

İstatistiğin Bilim ve Uygulamadaki Rolü................................... 7

Temel Kavramlar................................................................. 9

Bilginin Üretilmesinde Veri Biliminin Önemi.......................... 34

Gözlem Kuram İlişkisi ........................................................ 34

Bilimsel Araştırmanın Tasarımında Verinin Rolü ...................... 39

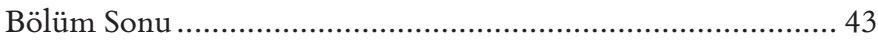

2.Bölüm Tanımlayıcı İstatistikler, Olasılık, Testler ve Analizler Elif BULUT

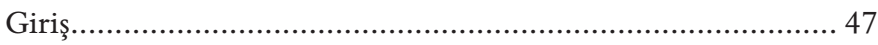

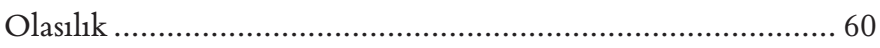

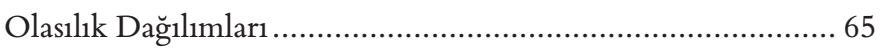

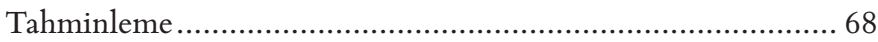

Örnekleme Dağılımları.......................................................... 70

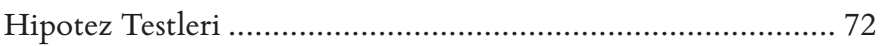

Regresyon ve Korelasyon Analizi ........................................... 77 


\section{Bölüm Soru ve Çözümler}

Elif BULUT

Soru ve Çözümler 85

\section{Bölüm İstatistiksel Okuryazarlık}

Ümit Remzi ERGÜN

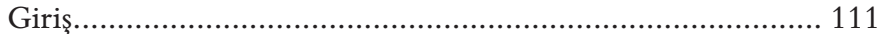

Literatürde İstatistiksel Okuryazarlık .................................. 113

İstatistiksel Okuryazarlığın Tanımı ....................................... 115

İstatistiksel Okuryazarlı̆̆ın Gereklilikleri ve Özellikleri......... 117

Bilişsel Yanlilık ve Korelasyon Yanılgisı .................................. 121

İstatistiksel Okuryazarlıkla Veri Yorumlama ve

Kantitatif Dürüstlük......................................................... 125

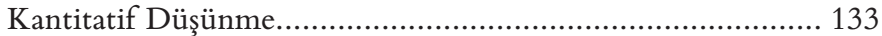

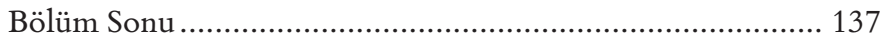

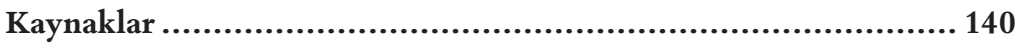




\section{KAYNAKLAR}

Akdeniz, F. (1984). Olasılık ve İstatistik. Ankara: Ankara Üniversitesi Basımevi

Akkaya, R. (2010). Olasılık ve İstatistik Öğrenme Alanındaki Kavramların Gerçekçi Matematik Eğitimi ve Yapılandırmacılık Kuramına Göre Bilgi Oluşturma Sürecinin İncelenmesi, Uludağ Üniversitesi Sosyal Bilimler Enstitüsü Doktora Tezi, Bursa.

Bakır, M. A. ve Aydın, C. (2013). İstatistik. Ankara: Nobel Yayınları.

Bayram, N. (2015). Araştırmalarda İstatistik ve Etik. İş, Güç, Endüstri İlişkileri ve İnsan Kaynakları Dergisi, 17 (3), 20-29

Biggeri, L.ve Zuliani, A. (1999). The Dissemination of statistical literacy among citizens and public administration directors, Paper Presented at the ISI 52nd Session Helsinki, Finland, 1-5.

Bolton, P. (2010). How to spot spin and inappropriate use of statistics, House of Commons Librariy: Statistical Literacy Guide, 1-9.

Çömlekçi, N. (2005). Temel İstatistik İlke ve Teknikleri. Eskişehir: Bilim ve Teknik Yayınevi.

Çömlekçi, N. (2001). Bilimsel Araştırma Yöntemi ve İstatistiksel Anlamlılık S1namaları. Eskişehir: Bilim Teknik Yayınevi

Davidian, M. (2013). The International Years of Statistics: A Celebration and A Call to Action. Journal of the American Statistical Association, 108:54, 1141-1146.

Dikmen, N. (2018). Ekonometriye Giriş, Ankara: Seçkin Yayıncılık.

Edwards, W. ve Winterfeldt, D. (1986). On Cognitive Illusions and Their Implications. (Derl.) İçinde, Arkes,H.,R.,ve Hammond,K.,R., Judgment and Decision Making: 643- 679.

Ener, M. ve Akcan, A. T. (2018). Makroekonomik Değişkenlerin İşsizlik ile İlişkisi: Türkiye Örneği. Yönetim Bilimleri Dergisi, 16 (31), 263-285.

Eyerci, C. (2021). Kurban Bayramının Kırmızı Et Fiyatlarına Etkisi. Kafkas Üniversitesi İktisadi ve İdari Bilimler Fakültesi Dergisi; 12 (23), 107-126.

Göktolga Z.G. (2013). İktisadi ve İdari Bilimler İçin İstatistik. Seçkin Yayınları.

Groebner D.F., Shannon P.W., Fry P.C., Smith K.D. (2011). Business Statistics, A Decision-Making Approach. Eight Edition, Pearson.

Gürsakal, N. (2012). Betimsel İstatistik. Bursa: Dora Yayınları

Gürtan, K. (1974). İstatistik ve Araştırma Metodları: İktisat ve İş İdaresine Tatbikatı. İstanbul: İstanbul Üniversitesi Yayınları

Haak, D. G. (1979), Teaching Statistical Literacy, Teaching Statistics 1(3) (1979), 74-76.

Heaton, H. (1985). Avrupa İktisat Tarihi. Ankara: Teori Yayınları. 
Helenius, R., D’amelio, A., Campos, P. ve Macfeely, S. (2016). ISLP Country Coordinators as Ambassadors of Statistical Literacy and Innovations. Statistics Education Research Journal, 19 (1), 120-136.

Illich, I. (2015). Şenlikli Toplum (Dördüncü baskıdan çev.: A. Kot). İstanbul: Ayrıntı Yayınları

Illowsjy B., Dean S. (2018). Introductory Statistics. Openstax.

Işı̆̆ıçok, E. (2009). İstatistiksel Bakış. Bursa: Marmara Kitapevi Yayınları.

İşçil, N. (1973). İstatistik Notları ve Uygulamaları. Kalite Matbaası.

Kalıpsız, A. (1988). İstatistik Yöntemler. Doyuran Matbaası.

Kara, T. ve Atasoy, E. (2018). Eğitim Coğrafyası Perspektifinden Çanakkale İli, Atatürk Üniversitesi Sosyal Bilimler Enstitüsü Dergisi, 22:2, 1233-1257.

Kavurmac1, C. ve Altıntaş F. (2017). Stratejik Karar Verme Sürecine Bilişsel Yaklaşim: Üst Kademe Yöneticiler Üzerine Nitel Bir Araştırma. Yönetim ve Ekonomi Araştırmaları Dergisi, 15 (3), 91-113.

Lehohla, P. (2002). Promoting Statistical Literacy: A South African perspective. İçinde B. Phillips, (Ed.), Proceedings of the Sixth International Conferences on Teaching Statistics. Voorburg, the Netherlands: International Statistical InstituteGal, I. International Statistical Review, 70(1), 1-25.

Perry, L. M. (1983). Statistical Literacy, ASA Proceedings of the Section of Statistical Education, 92-96.

Rao, C. R. (1999). Statistics and Truth Putting Change to World. Singapore: World Scientific Publishing Co.

Rumsey, D. J. (2002). Discussion: Statistical literacy: Implications for teaching, research and practice. International Statistical Review, 70, 32-36.

Savrul, K. B. (2016). AR-GE Yatırımlarının KOBİ'lerin Ekonomik Performansına Etkisi: Avrupa Birliği Ülkeleri Örneği. Avrasya Bilimler Akademisi İşletme ve İktisat Dergisi, (5):1, 1-17.

Schield, M. (2021). Statistical Literacy for Policy Markers. Statlit Site. http://www. statlit.org/pdf/2021-Schield-ISI.pdf (08.09.2021).

Snell, L. (1999). Using Chance Media to Promote Statistical Literacy. Paper Presented at the 1999 Joint Statistical Meetings, Dallas, TX. http://www.statlit.org/ pdf/1999SnellASA.pdf (28.08.2021)

Tomak, S. (2011). Girişimcilik ve Bilişsel Yanlılık. Girişimcilik ve Kalkınma Dergisi, 6 (1), 73-95.

Tuğluoğlu, F. (2012). Türkiye Cumhuriyeti'nin İkinci Nüfus Sayımı: 20 İlkteşrin 1935. Çağdaş Türkiye Araştırmaları Dergisi, 12 (25), 55-78.

Wallman, K. K. (1993). Enhancing Statistical Literacy: Enriching our society. Journal of the American Statistical Association, 88(421),1-8. 